\title{
Initial effects of fragmentation on the density of three neotropical primate species in two lowland forests of Colombia
}

\author{
Andres Link ${ }^{1,2, *}$, Ana Gabriela de Luna ${ }^{1,3}$, Felipe Alfonso ${ }^{4}$, Paola Giraldo-Beltran ${ }^{5}$, \\ Fernando Ramirez \\ ${ }^{1}$ Proyecto Primates, Carrera 11a No. 91-55, Bogotá, Colombia \\ ${ }^{2}$ Department of Anthropology, New York University, 25 Waverly Place, New York, New York 10003, USA \\ ${ }^{3}$ Facultad de Ciencias Biologicas, Universidad Complutense de Madrid, c/ Jose Antonio Novais n 2 Ciudad \\ Universitaria, Madrid 28040, Spain \\ ${ }^{4}$ Departamento de Biologia, Pontificia Universidad Javeriana, Carrera 7 No. 40-62, Bogota, Colombia \\ ${ }^{5}$ Programa de Agronomia, and ${ }^{6}$ Programa de Biologia, Universidad de Caldas, Calle 65 No. 26-10, Manizales, Colombia
}

\begin{abstract}
Fragmentation and habitat destruction are 2 factors driving the current decline of mammal populations. Spider monkeys Ateles spp. are some of the first neotropical mammals to go extinct after fragmentation, as they (1) are large-bodied, specialized frugivores that require large areas to subsist, (2) are preferred targets for local hunters, (3) have slow reproductive cycles, and (4) rarely move between adjacent forest fragments. Brown spider monkeys A. hybridus are Critically Endangered, and most of their historical habitat has either been cleared or is seriously fragmented. We conducted census surveys at 2 areas in Colombia (Las Quinchas and San Juan) in order to compare the population density of brown spider monkeys, red howler monkeys Alouatta seniculus, and whitefronted capuchins Cebus albifrons in both continuous forest and recently fragmented forest in each of these 2 areas. We found a higher density of brown spider monkeys and red howler monkeys in recent fragments at both sites, while differences were not consistent for white-fronted capuchins. We suggest that these patterns could be explained by the constrained ability of spider monkeys and howler monkeys to move between forest fragments and to exploit impacted or degraded areas. In the absence of hunting, the immediate effects of fragmentation on spider monkeys seem to lead to a sudden increase in population density as a result of a decreasing forested area, while maintaining population numbers relatively stable. Longer-term research will lead to the identification of the proximate factors leading to the generalized pattern of local extinction of spider monkey populations in small isolated fragments.
\end{abstract}

KEY WORDS: Ateles hybridus $\cdot$ Endangered species $\cdot$ Fragmentation $\cdot$ Line transects $\cdot$ Population density

\section{INTRODUCTION}

Habitat destruction is among the main factors driving the rapid decline of a large number of plants and animals in most of the planet's ecosystems (Fahrig 2002). The loss of natural habitats as well as their frag- mentation is exposing wildlife to rapidly emerging challenges, particularly for migratory species and those with large home ranges or 'specific' ecological requirements (Andrén 1994). The genetic and demographic consequences associated with these isolation processes have been described using the island bio- 
geographical theory (MacArthur \& Wilson 1967, Lovejoy et al. 1986, Soulé et al. 1988, Newmark 1996, Sih et al. 2000). Furthermore, as fragmentation increases and more areas become accessible and exposed to anthropogenic activities, wild populations become more vulnerable, especially when activities such as hunting (Michalski \& Peres 2005) or increased exposure to diseases (Chapman et al. 2006, Goldberg et al. 2008) have a direct and negative effect on their members. Although several studies have found support for the idea that fragmentation, in the long run, increases the probability of local extinctions for many birds and mammals (Andrén 1994, Fahrig 2002 and references therein), there is still a knowledge gap regarding the proximate factors driving these extinction processes.

Neotropical primates (infraorder Platyrrhini) are characterized as having evolved physical and behavioral adaptations for arboreality (Hershkovitz 1977), and all extant New World monkeys spend all or at least most of their time above ground on shrubs, trees, and lianas. For those species that occasionally do come to the ground for feeding or traveling, even subtle fragmentation can isolate previously neighboring individuals or groups (Chiarello \& de Melo 2001). Most New World monkeys rely on fruits, seeds, leaves, gum, and other plant parts as the most important items in their diets, and thus are directly affected when deforestation and habitat loss take place, causing resources to become scarce (Cowlishaw \& Dunbar 2000). As a result, arboreal primates are particularly vulnerable to local extinction as a result of fragmentation and habitat loss (Cowlishaw 1999).

Different primate species may adapt or respond differently to habitat loss and other anthropogenic interventions (Michalski \& Peres 2005). Large-bodied frugivorous primates are among the most vulnerable guilds when exposed to habitat disturbances and fragmentation, not only because they usually require large areas in order to meet their nutritional requirements, but also because given their large size, they are often preferred targets for hunters. Of neotropical primates, spider monkeys Ateles spp. are among the most fragile taxa, as they prefer undisturbed forests, are preferred hunting targets (Peres 2000, Peres \& Lake 2003), and are among the first animals to go locally extinct under such hunting pressure (Franzen 2006).

Spider monkeys also have additional biological characteristics that restrict their potential flexibility to adapt to habitat loss and fragmentation. First, their long reproductive cycles are only comparable to those of hominoids, after controlling for body size (Di Fiore \& Campbell 2007). Females first reproduce at approximately 7 to $9 \mathrm{yr}$ of age, and they have long average inter-birth intervals of 3 yr (Symington 1988). Thus, their populations are unable to recover in the short term from rapid population declines, especially if hunters target adult females, given their large body size (in comparison to most other primates) and the possibility of capturing offspring as pets (Cowlishaw \& Dunbar 2000, Duarte-Quiroga \& Estrada 2003, Franzen 2006). Second, spider monkeys are among the largest neotropical primates (ca. $8 \mathrm{~kg}$ ) and are ripefruit specialists (Dew 2005, Di Fiore et al. 2009), requiring large areas to obtain these resources. Thus, habitat fragmentation and habitat loss pose a significant challenge for these primates.

Folivorous and omnivorous primates are expected to cope better with habitat disturbance and fragmentation, as leaves and insects are more evenly distributed resources in tropical forests. Also, primates that are able to move between isolated forest fragments, crossing through disturbed areas (e.g. pastures or regenerating vegetation), are expected to be less affected by fragmentation processes. Howler monkeys Alouatta spp. are large folivorous primates found throughout the Neotropics, in both large and fragmented habitats (Di Fiore \& Campbell 2007). Capuchin monkeys Cebus spp. are omnivorous primates that include a large proportion of invertebrates and vertebrates in their diets and show ample resilience to habitat disturbance (Michalski \& Peres 2005).

The Inter-Andean lowland rainforests of Colombia have been exposed to human intervention for centuries. Nonetheless, the late twentieth century was marked by an accelerated process of habitat loss as forests were increasingly cut and transformed into pastures for extensive cattle ranching and agriculture (Vargas et al. 1998). In fact, Morales-Jimenez (2004) estimated that only $18 \%$ of the potential distribution of the forests where brown spider monkeys once lived still persists, and only $9 \%$ remains in large tracts of continuous forest. The increasing destruction of InterAndean forests is likely to drive the extinction of many taxa whose distribution is mostly limited to these forests, including the blue-billed curassow Crax alberti and the silvery-brown tamarin Saguinus leucopus and other endemic taxa, in addition to brown spider monkeys Ateles hybridus.

Currently, brown spider monkeys are considered Critically Endangered primates by the International Union for the Conservation of Nature and Natural Resources (IUCN: www.iucnredlist.org). Brown spider monkeys came to be considered a distinct primate species (Collins \& Dubach 2000) only about a decade ago, and almost no information existed on the ecology and social behavior of these endangered primates.

Although many studies have attempted to describe the behavioral changes or ecological strategies of pri- 
mates living in altered and fragmented habitats (Johns \& Skorupa 1987), few have assessed the effects of fragmentation on demography and population density. Several methods to estimate primate population densities have been developed and implemented, but there is still no consensus on which method provides the most accurate results (Marshall et al. 2008 and references therein). Accurate results have only been attained through direct counts (Defler \& Pintor 1985), but these methods are too costly to be implemented in large-scale studies. Thus, other methods such as home range analyses or line transect methods have been used more frequently. Home range analyses require enormous effort to obtain a sample size large enough (several overlapping groups) to be accurately extrapolated to the population level (Fashing \& Cords 2000), and most studies have relied on small samples to estimate 'real' population densities (Hassel-Finnegan et al. 2008). Within the wildlife biology literature, there is ample debate on the accuracy and precision of line transect methods due to the practical difficulties to comply with all required assumptions (Marshall et al. 2008). Nevertheless, line transect methods still remain the most used techniques for assessing primate population densities. Independent of their accuracy, these methods can be used to compare relative differences in population densities between different areas (assuming a similar precision in data collection).

The main objective of this study was to assess the initial effects of fragmentation and habitat loss on the population densities of brown spider monkeys Ateles hybridus, red howler monkeys Alouatta seniculus, and white-fronted capuchins Cebus albifrons in 2 lowland forests in Colombia. We evaluated the effects of fragmentation on primate population densities in a continuous forest and a recently fragmented forest in each of 2 areas within the Magdalena River Valley in Colombia. We describe differences in population density for 3 primate species in the initial phase of habitat reduction (soon after fragmentation took place) in order to build on our current knowledge of how fragmentation affects primate populations, and we discuss the potential factors that lead to the local extinction of primate populations in small isolated patches in the long run.

\section{MATERIALS AND METHODS}

Study sites. We collected data at 2 study areas characterized by a mosaic of forest fragments around larger patches of continuous forests: Serranía de Las Quinchas (hereafter 'Quinchas') and Hacienda San Juan de Carare (hereafter 'San Juan') (Fig. 1). The sites are ca. $75 \mathrm{~km}$ apart and comprise some of the

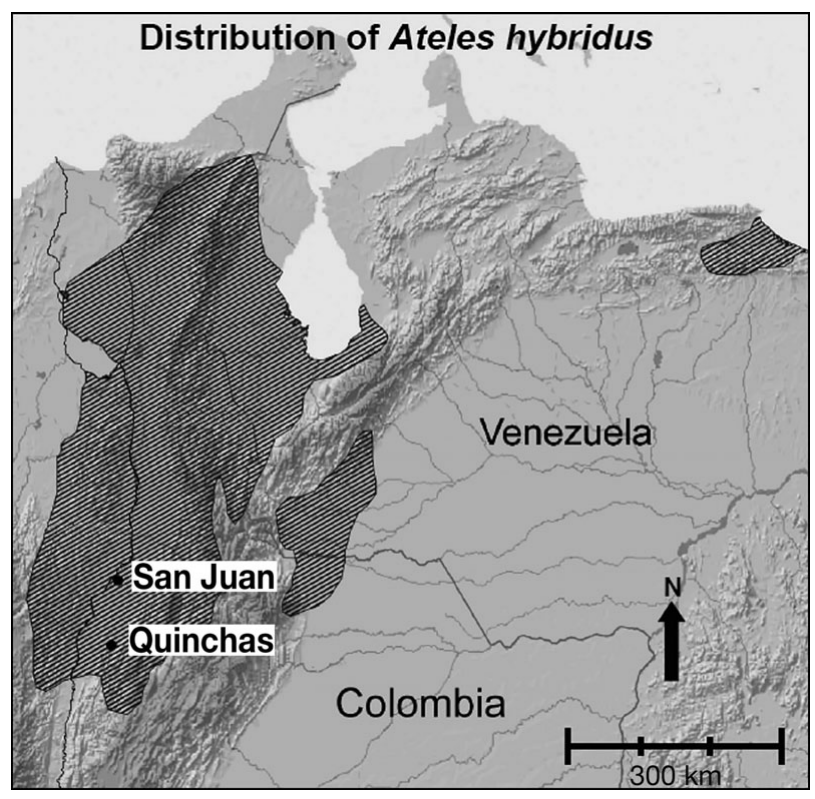

Fig. 1. Location of the 2 study sites in Colombia (San Juan and Quinchas). The shaded area represents the probable distribution of the brown spider monkey as published by the IUCN (2010)

last remains of lowland Inter-Andean rainforests in the Colombian Magdalena River valley region (Fig. 1). In each site, we conducted line transect surveys to estimate population densities of primates in one relatively large and continuous forest and another forest fragment that had recently been exposed to fragmentation and selective logging. We focused on surveying all diurnal primates in the region: brown spider monkeys, red howler monkeys, and white-fronted capuchins; grey-legged night monkeys Aotus griseimembra are present in the area but were not included in this study.

At Quinchas, we conducted census surveys at a fragmented forest within the private natural reserve 'El Paujil' (referred to here as 'Quinchas Fragment') owned by Fundacion ProAves, where we have been studying brown spider monkeys since 2005, and at a section of a continuous private forest at Vereda La Guinea (referred to here as 'Quinchas Continuous'). Both sites are on the western slope of the eastern Andes and are situated approximately $7 \mathrm{~km}$ from each other. At the time of the study, both sites had been exposed to selective logging. Although hunting of brown spider monkeys had been prohibited in the region, it still occurs at a very low frequency. The terrain of the region is characterized by narrow ridges intersected by steep riverine valleys. A trail system was established at each site and was mapped and marked every $25 \mathrm{~m}$ with flagging tape. Annual rainfall averaged $3544 \pm 336 \mathrm{~mm}(\mathrm{n}=3 ; 2006$ to 2008$)$ with few 
months receiving less than $100 \mathrm{~mm}$ (3 out of 36). The dry season occurs during the months of December to February.

Quinchas Fragment, La Reserva $\left(06^{\circ} 03^{\prime} \mathrm{N}, 74^{\circ} 16^{\prime} \mathrm{W}\right)$, is located at Puerto Pinzon, Boyacá Department, and comprises 2 adjacent forest fragments of 20 and 60 ha that were isolated for several years from an adjacent ca. 300 ha fragment by a road. The fragments have recently been reconnected with the larger fragment at ca. 5 points through natural 'bridges' in the canopy that allow spider monkeys to cross the road and move between fragments. The site is located in the northwestern part of Serranía de Las Quinchas between 200 and $350 \mathrm{~m}$ a.s.l. Selective logging was widespread around a decade ago, but since 2003 the site has been owned by Fundación ProAves and has been protected from logging and hunting.

Quinchas Continuous, La Guinea $\left(06^{\circ} 01^{\prime} \mathrm{N}\right.$, $74^{\circ} 12^{\prime} \mathrm{W}$ ), is located in a central part of the Serranía de Las Quinchas at Bolivar, Santander, between 200 and $700 \mathrm{~m}$ a.s.l., and access to the forest is restricted to mules or trekking due to the rough terrain. At the time of the study, the area was privately owned and part of it had been transformed into pastures for cattle ranching. Nonetheless, the study area was connected to a large and continuous forest of ca. 80000 ha that was experiencing selective logging of hardwoods.

At Hacienda San Juan de Carare, we conducted census surveys at a fragmented seasonally flooded forest patch (referred to hereafter as 'San Juan Fragment') where we have been studying brown spider monkeys since 2007, and in a larger forest fragment (referred to hereafter as 'San Juan Continuous') that consists of a mosaic of terra-firme forest and seasonally flooded forests. The sites are approximately $3 \mathrm{~km}$ apart and the terrain is relatively flat. San Juan is located near the Magdalena River in the middle of the Magdalena valley between the eastern and central Andes of Colombia. Mean rainfall is $2070 \mathrm{~mm}$ (IDEAM 2008), and average temperature oscillates around $28^{\circ} \mathrm{C}$.

San Juan Fragment $\left(06^{\circ} 43^{\prime} \mathrm{N}, 74^{\circ} 09^{\prime} \mathrm{W}\right)$ is a thin, riverine forest fragment of roughly 70 ha that runs along the San Juan River and was recently (ca. 3 yr ago) fragmented in the northern and southernmost part of the current forest by man-made pastures. Natural flooded savannas in the west and the San Juan River in the east also define the forest fragment. Selective logging has occurred in the fragment, although large emergent trees (e.g. Ficus insipida) are still present.

San Juan Continuous $\left(06^{\circ} 42^{\prime} \mathrm{N}, 74^{\circ} 08^{\prime} \mathrm{W}\right)$ is one of the largest forest patches in the region, comprising ca. 1500 ha. The area has recently been exposed to selective logging and is surrounded by pastures for cattle ranching and natural savannas.
Demographic data. We habituated and studied the only group of brown spider monkeys living at Quinchas Fragment from January 2006 onwards; the 2 social groups of spider monkeys in San Juan Fragment have been habituated and studied since September 2007. Demographic, ranging, and other ecological data have been systematically collected over approx $485 \mathrm{~h}$ of behavioral 'follows' in San Juan, and $847 \mathrm{~h}$ at Quinchas. Spider monkeys from these 3 social groups have been individually identified based on differences in their facial and ano-genital patterns. Births, disappearances, and emigration events have been monitored during this time.

Primate density. Population density surveys were calculated following the line transect method and following the recommendations suggested by Peres (1999). Data were collected during approximately $8 \mathrm{~d}$ each month from August 2007 to August 2008 for a total of $954.24 \mathrm{~km}$ walked during 239 walks. Sampling at San Juan was somewhat less intensive than sampling at Quinchas, as the region had extended periods of floods that prevented us from doing the surveys. Transects were walked from 06:00 to 10:00 $\mathrm{h}$ at a speed of approximately $1 \mathrm{~km} \mathrm{~h}^{-1}$ stopping every $100 \mathrm{~m}$ and waiting 5 min in silence looking for any animal that could be resting over the transect, and trying to detect any movement or sound. In the case of rain, censuses were interrupted until the weather allowed us to continue. Upon detecting a primate group, we waited from 5 to $10 \mathrm{~min}$ in order to increase the chance of detecting all members of the group. When a group of primates was encountered, we recorded the time, number of individuals, the perpendicular distance of the group's center to the transect, the location, and the sex-age category of each individual if possible. Cluster size represents the number of individuals in a group or subgroup of primates that were detected during census surveys. For howler monkeys, cluster size represents the size of the social groups (which are cohesive), while for spider monkeys it represents the size of traveling or foraging subgroups (given their fission-fusion grouping patterns). For capuchins, it attempts to represent the size of the social group, but given the large group spread in this taxon, data presented here were taken on subgroups of capuchins.

We calculated primate density and cluster size from line transect data for each species separately, using different analytical methods: (1) Distance 5.0 (Thomas et al. 2006), (2) the Kelker method based on perpendicular distances, and (3) the King estimator (Leopold 1933). For the Distance method, we used the distance sampling function of the program, testing 5 candidate models in the program for fit to the distribution of transect data, including the default half-normal key with cosine polynomial expansion, uniform key with 
cosine polynomial expansion, uniform key with simple polynomial expansion, half-normal key with hermite polynomial expansion, and hazard-rate key with the cosine polynomial expansion. We selected the model with the lowest Akaike's information criterion (AIC) value (Buckland et al. 2001). The cluster size was calculated using the cluster size-biased regression method unless warnings indicated the need to use the mean of the observed clusters. For Distancebased analyses, we truncated $5 \%$ of the data as suggested by Buckland et al. (2001) to exclude potential outliers.

For the Kelker method, we used the equation:

$$
D=n / 2 L a
$$

where $D$ is the density of individuals or groups per unit area, $n$ is the number of individuals or groups along the transect, $L$ is the total length of the transect, and $a$ equals half the effective strip width.

To obtain the species-specific strip width by the Kelker method, the cutoff point was determined by analyzing the distribution of perpendicular distances as described by Hassel-Finnegan et al. (2008) and Marshall et al. (2008). We selected the histogram used for each analysis on the basis of which block width resulted in the clearest detection cutoff point up to where we assumed that the probability of detection was 1 . We included all sightings up to the cutoff point, but excluded sightings beyond the cutoff point for analyses.

When using the King estimator, we used the same density formula as in the Kelker method; however, the effective strip width was calculated as the average perpendicular distance recorded for a given species at each site. For both the Kelker and King methods, the mean subgroup size was calculated based on all groups observed within the effective strip width, using the maximum number of individuals measured for all calculations.

Finally, in the San Juan Fragment, we were able to directly count all individual spider monkeys living in the fragment and were thus able to compare the results of the density estimates obtained through the different methods to the 'real' density of spider monkeys in the fragment. To estimate the accuracy of the different methods, we estimated the deviation from the results obtained from each method to the known density of spider monkeys at San Juan Fragment. We used the following equation:

$$
\text { Deviation between methods }=([D t-D r] / D r) \times 100
$$

where $D t=$ estimated density and $D r=$ known 'real' density of spider monkeys at San Juan Fragment. All statistical analyses were performed using SPSS 13.0 .

\section{RESULTS}

\section{Direct counts}

From our long-term research at Quinchas and in the San Juan forest fragments, we were able to directly count the number of individuals (through individual identification) living in the groups that overlapped with our census transects. At the time of the study, there was 1 group of 29 spider monkeys at Quinchas and 2 groups of 16 and 14 spider monkeys in the 2 social groups living in the San Juan Fragment. Nevertheless, we were only able to estimate the true density of spider monkeys at San Juan, as the fragment in Quinchas re-connected (after several years of isolation) to adjacent and relatively inaccessible fragments (to observers), and thus our study group expanded its previously restricted home range. The forest fragment at San Juan has an area of $0.70 \mathrm{~km}^{2}$ where 30 spider monkeys were living at the time of this study, giving a density of 42.8 ind. $\mathrm{km}^{-2}$.

\section{Density estimates}

We recorded a total of 640 sightings of primates in ca. $954 \mathrm{~km}$ of transect surveys at the 4 census surveys included in this study. Overall, white-fronted capuchins were observed most frequently ( $n=264$ encounters), followed by brown spider monkeys ( $\mathrm{n}=223$ ) and red howler monkeys $(n=153)$. The number of censuses and the total sampling effort was unequal for each site, and results are given in Table 1.

At Quinchas, spider monkeys and howler monkeys were more frequently encountered in recently formed fragments (while controlling for sampling effort), while capuchins were more frequently observed in the continuous forests. In a similar pattern, spider monkeys and howler monkeys were much more frequently encountered in the forest fragment at San Juan when compared to the more continuous forests, although capuchins had similar rates of encounter in both forests (Table 1). During census surveys and opportunistic observations, we recorded several groups of night monkeys Aotus griseimembra, confirming their presence in all 4 study areas.

Given the low number of sightings of spider monkeys in San Juan Continuous $(\mathrm{n}=6)$ and of howler monkeys in Quinchas ( $\mathrm{n}=13$ ) and in San Juan Continuous $(\mathrm{n}=3$ ) during the census surveys, we were unable to use Distance-based analyses for these taxa at those sites. Thus, we relied on estimating their densities only via the Kelker and King methods using perpendicular distances to the transect (Aldana et al. 2008, Hassel-Finnegan 2008). 
Even though there were marked differences in the density estimates of all taxa based on the different methods of data analysis (Table 2), we found a consistent pattern of higher group density for both spider monkeys and howler monkeys in recently fragmented forests than in the more continuous forests at both Quinchas and San Juan (Fig. 2). Differences in the rate of encounter of Ateles hybridus and Alouatta seniculus between fragmented and continuous forests were more striking at San Juan than at Quinchas. This pattern was not observed for capuchin monkeys, which showed less dramatic differences in group density between recent forest fragments and continuous forests. In fact, at Quinchas, capuchin monkey groups had higher densities in continuous forests, and at San Juan there were no differences in group density between fragmented and continuous forests (Fig. 2).

Table 1. Ateles hybridus, Alouatta seniculus, and Cebus albifrons. Site size, sampling effort, and sightings of brown spider monkeys, red howler monkeys and white-fronted capuchins in a continuous and fragmented forest at Quinchas and San Juan, Colombia. Sightings are total nos. followed by mean per km in parentheses

\begin{tabular}{|c|c|c|c|c|}
\hline & \multicolumn{2}{|c|}{ —uinchas } & \multicolumn{2}{|c|}{ San Juan } \\
\hline & Continuous & Fragment & Continuous & Fragment \\
\hline Site size (ha) & 80000 & $\sim 400$ & $\sim 1500$ & 70 \\
\hline Transect distance $(\mathrm{km})$ & 4.725 & 3.825 & 3.534 & 3.258 \\
\hline No. of censuses & 81 & 85 & 31 & 42 \\
\hline Sampling effort (km) & 382.725 & 325.125 & 109.554 & 136.836 \\
\hline Sightings of A. hybridus & $75(0.20)$ & $85(0.26)$ & $6(0.05)$ & $57(0.42)$ \\
\hline Sightings of $A$. seniculus & $13(0.03)$ & $32(0.10)$ & $3(0.03)$ & $105(0.77)$ \\
\hline Sightings of C. albifrons & $90(0.24)$ & $47(0.14)$ & $55(0.50)$ & $72(0.53)$ \\
\hline
\end{tabular}

Table 2. Ateles hybridus, Alouatta seniculus, and Cebus albifrons. Estimates of population density (ind. $\mathrm{km}^{-2}$ ) of brown spider monkeys, red howler monkeys, and white-fronted capuchins in the 4 forests surveyed and calculated using the 4 methods Distance, Kelker, King and direct counts (see 'Materials and methods; Primate density'). nd: not determined

\begin{tabular}{|lccccc|}
\hline \multirow{2}{*}{ Method } & \multicolumn{3}{c}{ Quinchas } & & \multicolumn{2}{c|}{ San Juan } \\
\cline { 2 - 3 } & Continuous & Fragmented & & Continuous & Fragmented \\
Ateles hybridus & & & & & \\
Distance & 12.3 & 27.1 & & 3.7 & 21.8 \\
Kelker & 12.1 & 27.0 & & 3.3 & 25.0 \\
King & 26.1 & 41.1 & & 5.2 & 33.0 \\
Direct count & nd & nd & & nd & 42.8 \\
Alouatta seniculus & & & & \\
Distance & 1.9 & 7.9 & & 1.6 & 60.2 \\
Kelker & 1.8 & 8.7 & & 1.5 & 64.0 \\
King & 3.7 & 15.6 & & 2.5 & 98.3 \\
Direct count & nd & nd & & nd & nd \\
Cebus albifrons & & & & \\
Distance & 29.4 & 19.6 & & 98.4 & 116.6 \\
Kelker & 29.8 & 22.9 & & 82.8 & 56.3 \\
King & 59.2 & 35.9 & & 138.6 & 130.3 \\
Direct count & nd & nd & nd & nd \\
\hline
\end{tabular}

Brown spider monkeys were found in subgroups that averaged $( \pm \mathrm{SD}) 3.9( \pm 2.9)$ ind. and ranged from 17 ind. Howler monkey group size was on averwith $5.8( \pm 4.0)$ ind, and groups ranged in size from 1 to 21 ind. Spider monkey subgroup size did not differ significantly between sites (Kruskal-Wallis test: spider monkeys $\left.\chi^{2}=0.153, \mathrm{n}=205, \mathrm{p}=0.985\right)$, but the same was not true for howlers and capuchins. Howler monkeys were found in bigger groups in the uinchas fragment and small groups in the continuforests. On the other hand, capuchin clusters continuous forests (Kruskal-Wallis test: howler monkeys $\chi^{2}=25.83, \mathrm{n}=146, \mathrm{p}<0.001$; capuchins $\chi^{2}=$ 7.82, $\mathrm{n}=226, \mathrm{p}=0.05$ ). (Fig. 3).

Due to the relatively small differences in group or subgroup size for each primate species across all 4 forests, the results of primate density (ind. $\mathrm{km}^{-2}$ ) are similar to those reported for group density, only scaled up by a factor associated with average cluster size. Spider monkey and howler monkey population densities were higher in fragments than in continuous forests, especially at San Juan (Table 2). On the other hand, capuchins seemed to be responding in a different way to fragmentation, since their densities were very similar between fragments and continuous forests. Moreover, capuchin densities were overall significantly higher in San Juan compared to Quinchas.

When comparing the different line transect methods to the true density of spider monkeys in San Juan Fragment, all methods underestimated the population density of 42.8 ind. $\mathrm{km}^{-2}$. The density estimated by the King method (33.0 ind. $\mathrm{km}^{-2}$ ) was closest to the direct count, showing an underestimation of $23 \%$. The Kelker and DISTANCE methods yielded very similar results for all species and sites, but underestimated the true population density at San Juan by over $40 \%$. When comparing density estimates between methods, results obtained with the King method were statistically different from those obtained with Kelker and Distance, which on the other hand were not statistically 


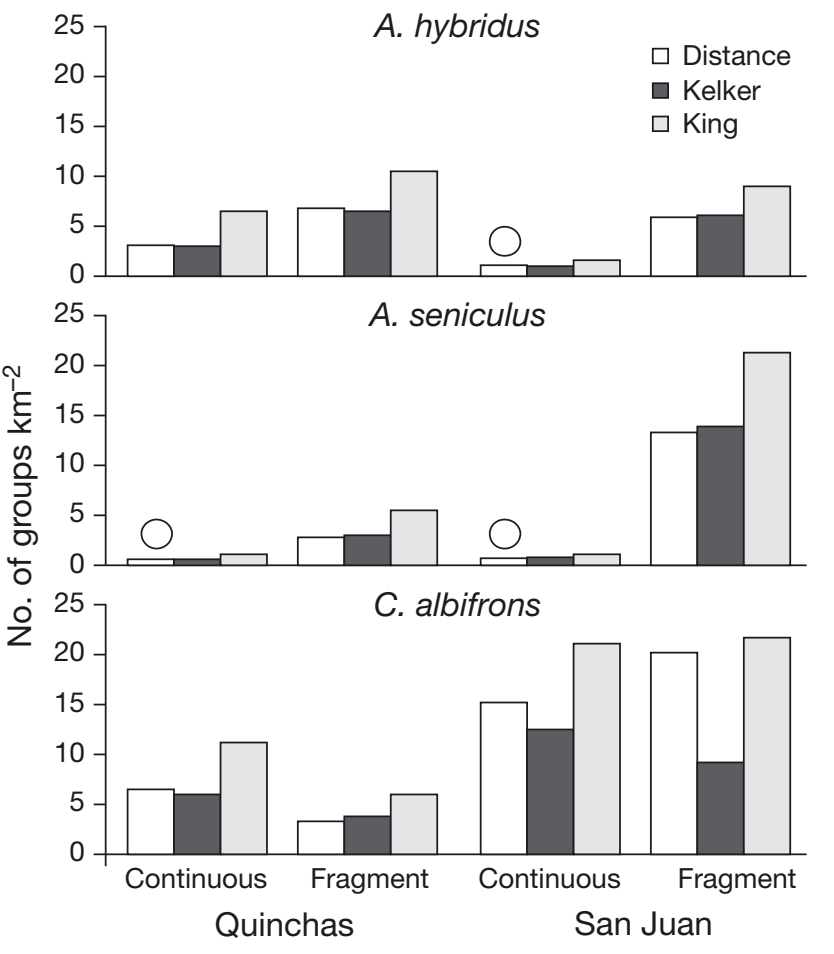

Fig. 2. Ateles hybridus, Alouatta seniculus, and Cebus albifrons. Group densities estimated with 3 different methods for diurnal primates in 4 different forests. Circles represent data obtained with the Distance method using small sample size

different from one another (Wilcoxon signed ranks test: Distance-King $Z=-3.06, \mathrm{n}=12$, $\mathrm{p}=0.002$; Kelker-King $Z=-3.06, \mathrm{n}=12, \mathrm{p}=0.002$; Kelker-Distance $Z=-0.39, \mathrm{n}=12, \mathrm{p}=0.695$ ).

\section{DISCUSSION}

Our results suggest that primate species differ in their ability to respond to recent fragmentation and habitat disturbance, as has been suggested in previous studies (Cowlishaw \& Dunbar 2000 and references therein). As described above, spider monkeys and howler monkeys had higher densities in recent forest fragments compared to continuous forests, while capuchin monkeys showed no marked differences in their population densities between continuous and fragmented areas. The apparently better ability of capuchin monkeys to cope with fragmentation could be related to 2 main factors. First, capuchins are omnivorous primates that rely on a wide variety of food items in their diets, including fruits, seeds, and invertebrate and vertebrate prey (Siemers 2000); thus they can exploit a wider variety of habitats and still find enough food to supply their energetic requirements. Second, capuchins are frequently observed on the ground and have fewer limitations than most other
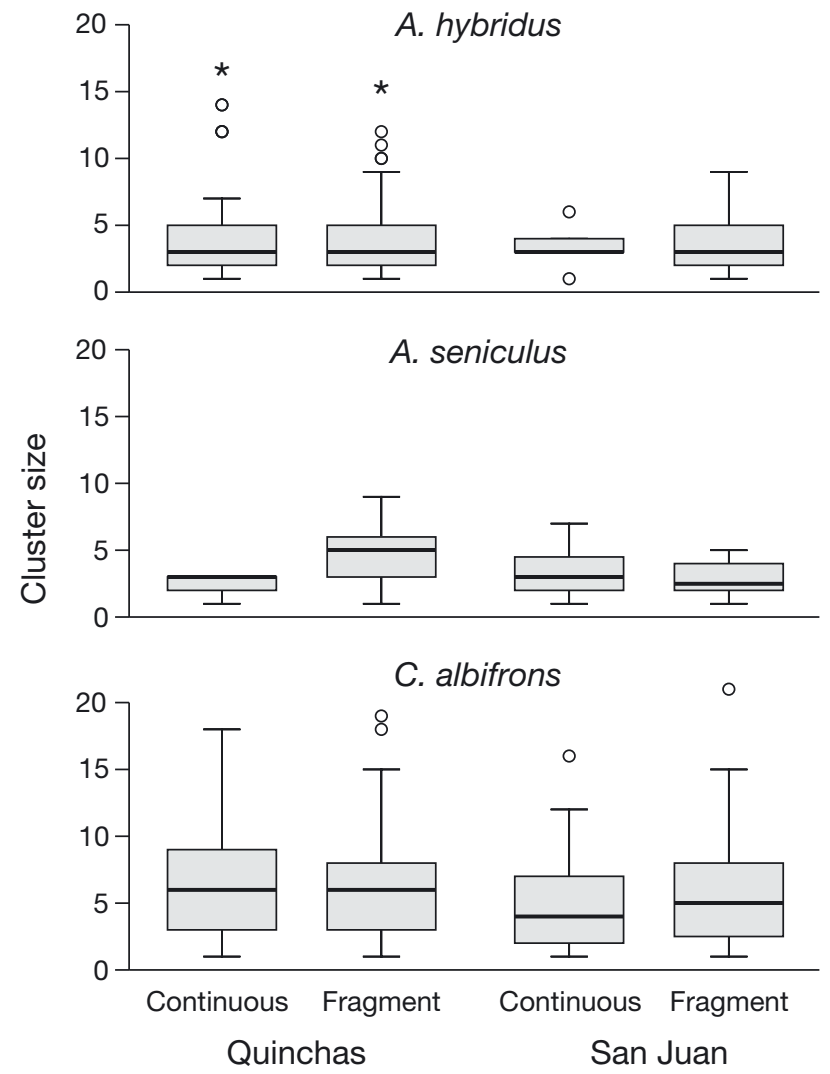

Fig. 3. Ateles hybridus, Alouatta seniculus, and Cebus albifrons. Cluster sizes (no. of individuals) for brown spider monkeys, red howler monkeys, and white-fronted capuchins in the 4 forests. The box plots show the median and 25th and 75th percentiles; whiskers represent all data except extreme values, circles show outliers (1.5 to 3 times the interquartile ranges), and asterisks are data 3 or more times the interquartile range

neotropical primates in their ability to move between nearby forest fragments over small savanna, swamps, or bushy areas or even man-made pastures (Brown \& Zunino 1990, Siemers 2000). In fact, capuchin monkeys were found to occupy the largest proportion of forest fragments of different size (range 0.47 to 13551 ha) from a large set of carnivores and primates in southern Amazonia. Out of 129 forests surveyed, capuchins were only absent in 3 small fragments, but were present in most other fragments, even those as small as $<1$ ha (Michalski \& Peres 2005). These results suggest that capuchins have the ability to cope with fragmentation by using disturbed areas to move among patches of more intact forest and might also be able to exploit food resources in these altered habitats. These facts are consistent with our results showing similar population densities in both continuous forests and forest fragments, suggesting a more homogeneous distribution of the capuchin population in habitats comprised of a mosaic of small forest fragments and larger forests. 
Brown spider monkeys and red howler monkeys seemed to be more severely affected by habitat loss and fragmentation. For both taxa, we found higher population densities in the recently fragmented forests, suggesting that the population has been exposed to a reduction of habitat and highlighting the limited dispersal opportunities available for individuals of these taxa. In fact, differences in densities between fragments and continuous forest were more pronounced at San Juan, where the forest fragment has been isolated from all other forests nearby for ca. $3 \mathrm{yr}$, compared to the Quinchas Fragment that was isolated for several years beginning approximately 10 yr ago and was then re-connected during the study period to an adjacent fragment. Nevertheless, it remains unclear to what extent this isolation affects each species. Long-term surveys are currently underway in order to understand the long-term effects of fragmentation on these primate populations. Thus, continuous monitoring of primate population dynamics after fragmentation is needed to understand why some species such as spider monkeys Ateles spp. are absent from most small forest fragments (e.g. Estrada \& Coates-Estrada 1996, Cowlishaw \& Dunbar 2000, Michalski \& Peres 2005)

Folivorous primates are expected to respond better to habitat disturbances than are frugivorous primates, especially to habitat loss or fragmentation (Cowlishaw \& Dunbar 2000). Folivorous primates such as howler monkeys have been proposed to 'minimize energy expenditure' (Strier 1992), and have extended periods of rest during which fermentation takes place. Several studies have focused on howler monkeys living in, and able to survive in, small fragments (Estrada \& CoatesEstrada 1996). That they can do so is probably due to the fact that leaves (their most important food item) are more readily available and evenly distributed in space and time in tropical forests (Chapman 1988). On the other hand, large-bodied frugivorous primates, such as spider monkeys, have evolved behavioral patterns associated with 'maximizing energy intake' (Strier 1992). Spider monkeys move fast and efficiently over long distances in the forest canopy in order to find spatially clumped but sparse resources. Furthermore, spider monkeys have a specialized digestive system with fast retention times that allows them to process large quantities of fruits in short periods of time (Link \& Di Fiore 2006). As ripe fruit specialists and canopy dwellers, spider monkeys have been identified as species strongly affected by habitat fragmentation (Estrada \& Coates-Estrada 1996, Cowlishaw \& Dunbar 2000).

Our results showing higher densities of Ateles spp. and Alouatta spp. in fragmented areas seem contradictory at first, as most studies have documented that primate abundance correlates positively with patch size (Medley 1993, Estrada \& Coates-Estrada 1996, Wieczkowski 2004). On the other hand, Lovejoy et al. (1986) proposed that secondary vegetation at forest fragment edges might increase resources available to folivores. Nonetheless, we caution that our results reflect the initial response of primate population density when exposed to fragmentation (same number of primates restricted to smaller areas), and before other direct threats might come into play (e.g. hunting, diseases). This is especially true for spider monkeys that have been found to be among the first species to disappear as fragmentation and habitat disturbance increase (Estrada \& Coates-Estrada 1996, Peres \& Lake 2003).

The results described in this study showing higher densities of primates soon after fragmentation takes place, coupled with the general pattern of local extinction of spider monkeys in small fragments (Michalski \& Peres 2005), sets an initial framework to begin research on the proximate factors that potentially drive the local extinction of vulnerable taxa in fragmented landscapes (Fig. 4). The most relevant potential and non-exclusive factors proposed to influence local extinction of spider monkeys from small fragments are (1) hunting, as fragmentation increases the potential area accessed by hunters (Peres \& Lake 2003), (2) a decrease in food availability leading to resource scarcity and intra- and interspecific competition, (3) higher exposure to diseases (Chapman et al. 2006, Goldberg et al. 2008), and (4) genetic inbreeding and loss of population viability.

Most studies involving line transect methods have had to face limitations on the applicability of their results, given their variable accuracy in describing the true densities of wild populations (Marshall et al. 2008). It is difficult to rely on these methods, as most studies have different results supporting different methods as the most accurate. Nevertheless, to date they have been widely used and probably still are con-

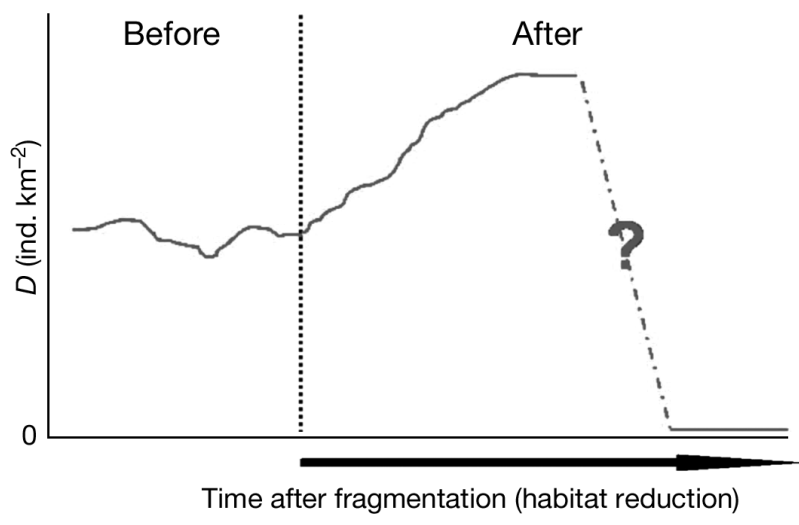

Fig. 4. Ateles spp. Effects of fragmentation on the population density $(D)$ of spider monkeys. Factors leading to population declines are still largely unknown 
sidered to be the most practical methods to estimate population densities in large areas (Peres 1999). Thus, in our study we have restrained from estimating population numbers in the different areas (even though such information is relevant to the development of conservation action plans), since the differences in density estimates produced by different methods were significant. When comparing the direct count of primates at San Juan fragment with the different population density estimate methods, we found that the King method yielded a somewhat more accurate estimate of the true number of spider monkeys resident in the fragment.

Despite the small sample size, the fact that the pattern of our results is consistent amongst sites in showing larger densities of Ateles hybridus and Alouatta seniculus, but not of Cebus albifrons, in recently fragmented areas allows an initial hypothesis about the effects of fragmentation on these species which will be tested as more data become available.

\section{CONCLUSIONS}

This study builds on our current understanding of how primates, in particular Critically Endangered brown spider monkeys, are affected by ongoing habitat loss and fragmentation. This information is of special interest when considering that one of the main causes of this species' disappearance is habitat loss (Urbani et al. 2008). Our results show that the first effect observed on the population densities of primates that are unable to easily move between fragments (e.g. Ateles hybridus and Alouatta seniculus) and are subject to little hunting pressure, is an increase in population density. Even though the process of logging or habitat destruction might not directly 'kill' the primates present in the area, such activities force them to progressively move to areas with remaining forest cover, thus maintaining the population numbers and territorial behavior in a decreasing forested area. Long-term effects of fragmentation still need to be addressed by long-term studies. Our results will provide the basis for more focused future research on the long-term effects of fragmentation on primate populations as well as on the flexibility of spider, howler, and capuchin monkeys to cope with habitat disturbance. These data will prove useful in the implementation of successful conservation strategies for brown spider monkeys in the fragmented landscapes where they are currently living.

Acknowledgements. We thank all students and collaborators of Proyecto Primates who contributed to this research project and to the conservation of brown spider monkeys in Colombia. We especially thank N. Galvis, B. Villanueva, and M.C. Diaz, who helped with data collection in the field. We also thank Fundación ProAves for allowing us to work at 'Reserva Natural de Aves El Paujil' and in particular E. Machado and E. Montero, who provided us with logistic support throughout the study. The Vargas, Lalinde, and De Greiff families also collaborated with us at La Guinea and San Juan. We thank A. Di Fiore and 2 anonymous reviewers for comments on earlier versions of this manuscript. This research project was funded by the Research Fellowship Program (WCS), Rufford Small Grants Foundation, Conservation International, Primate Conservation Inc., and Idea Wild.

\section{LITERATURE CITED}

Aldana AM, Beltran M, Torres-Neira J, Stevenson PR (2008) Habitat characterization and population densities of brown spider monkeys (Ateles hybridus) in Magdalena Valley, Colombia. Neotrop Primates 15:46-49

Andrén H (1994) Effects of habitat fragmentation on birds and mammals in landscapes with different proportions of suitable habitat: a review. Oikos 71:355-366

Brown AD, Zunino GE (1990) Dietary variability in Cebus apella in extreme habitats: evidence for adaptability. Folia Primatol 54:187-195

Buckland ST, Anderson DR, Burnham KP, Laake JL, Borchers DL, Thomas L (2001) Introduction to distance sampling: estimating abundance of biological populations. Oxford University Press, Oxford

> Chapman CA (1988) Patterns of foraging and range use by three species of neotropical primates. Primates 29:177-194

Chapman CA, Wasserman MD, Gillespie TR, Speirs ML, Lawes MJ, Saj TL, Ziegler TE (2006) Do nutrition, parasitism, and stress have synergistic effects on red colobus populations living in forest fragments? Am J Phys Anthropol 131:525-534

> Chiarello AG, de Melo FR (2001) Primate population densities and sizes in Atlantic forest remnants of Northern Espírito Santo, Brazil. Int J Primatol 22:379-396

> Collins AC, Dubach JM (2000) Phylogenetic relationships of spider monkeys (Ateles sp.) based on mitochondrial DNA variation. Int J Primatol 21:381-420

Cowlishaw G (1999) Predicting the pattern of decline of African primate diversity: an extinction debt from historical deforestation. Conserv Biol 13:1183-1193

Cowlishaw G, Dunbar RIM (2000) Primate conservation biology. University of Chicago Press, Chicago, IL

> Defler TR, Pintor D (1985) Censusing primates by transect in a forest of known primate density. Int J Primatol 6:243-259

Dew JL (2005) Foraging, food choice, and food processing by sympatric ripe-fruit specialists: Lagothrix lagotricha poeppigii and Ateles belzebuth belzebuth. Int J Primatol 26: $1107-1135$

Di Fiore A, Campbell CJ (2007) The Atelines: variation in ecology, behavior, and social organization. In: Campbell CJ, Fuentes A, MacKinnon KC, Panger M, Beader SK (eds) Primates in perspective. Oxford University Press, New York, NY, p 155-185

Di Fiore A, Link A, Schmitt CA, Spehar SN (2009) Dispersal patterns in sympatric woolly and spider monkeys: integrating molecular and observational data. Behaviour 146: $437-470$

> Duarte-Quiroga A, Estrada A (2003) Primates as pets in Mexico City: an assessment of the species involved, source of origin, and general aspects of treatment. Am J Primatol 61:53-60

Estrada A, Coates-Estrada R (1996) Tropical rain forest fragmentation and wild populations of primates at Los Tuxtlas, Mexico. Int J Primatol 17:759-783 
Fahrig L (2002) Effect of habitat fragmentation on the extinction threshold: a synthesis. Ecol Appl 12:346-353

Fashing PJ, Cords M (2000) Diurnal primate densities and biomass in the Kakamega Forest: an evaluation of census methodology. Am J Primatol 50:139-152

Franzen M (2006) Evaluating the sustainability of hunting: a comparison of harvest profiles across three Huaorani communities. Environ Conserv 33:36-45

Goldberg TL, Gillespie TR, Rwego IB, Esoff EL, Chapman CA (2008) Forest fragmentation as cause of bacterial transmission among nonhuman primates, humans and livestock, Uganda. Emerg Infect Dis 14:1375-1384

Hassel-Finnegan HM, Borries C, Larney E, Umponjan M, Koenig A (2008) How reliable are density estimates for diurnal primates? Int J Primatol 29:1175-1187

Hershkovitz P (1977) Living New World monkeys (Platyrrhini): with an introduction to primates, Vol 1. University of Chicago, Chicago, IL

IDEAM (Instituto de Hidrología, Meteorología y Estudios Ambientales de Colombia) (2008) www.ideam.gov.co

IUCN (2010) IUCN Red List of Threatened Species. Version 2010.4. www.iucnredlist.org (accessed 27 October, 2010)

- Johns AD, Skorupa JP (1987) Responses of rain-forest primates to habitat disturbance: a review. Int J Primatol 8: $157-191$

Leopold A (1933) Game management. Charles Scribner's Sons, New York, NY

Link A, Di Fiore A (2006) Seed dispersal by spider monkeys and its importance in the maintenance of neotropical rainforest diversity. J Trop Ecol 22:235-246

Lovejoy TE, Bierregaard RO Jr, Rylands AB, Malcolm JR and others (1986) Edge and other effects of isolation on Amazon forest fragments. In: Soulé ME (ed) Conservation biology: the science of scarcity and diversity. Sinauer, Sunderland, MA, p 257-325

MacArthur RH, Wilson EO (1967) The theory of island biogeography. Princeton University Press, Princeton, NJ

Marshall AR, Lovett JC, White PCL (2008) Selection of linetransect methods for estimating the density of groupliving animals: lessons from the primates. Am J Primatol 70:452-462

Medley KE (1993) Primate conservation along the Tana River, Kenya: an examination of the forest habitat. Conserv Biol 7:109-121

Michalski F, Peres CA (2005) Anthropogenic determinants of primate and carnivore local extinctions in a fragmented forest landscape of southern Amazonia. Biol Conserv 124: 383-396

Editorial responsibility: Anna Nekaris, Oxford, UK
Morales-Jimenez AL (2004) Modeling distributions for Colombian spider monkeys (Ateles sp.) using GARP and GIS to find priority areas for conservation. MSc thesis, Oxford Brookes University, Oxford

- Newmark WD (1996) Insularization of Tanzanian parks and the local extinction of large mammals. Conserv Biol 10: $1549-1556$

Peres CA (1999) General guidelines for standardizing linetransect surveys of tropical forest primates. Neotrop Primates 7:11-16

Peres CA (2000) Effects of subsistence hunting on vertebrate community structure in Amazonian forests. Conserv Biol $14: 240-253$

Peres CA, Lake IR (2003) Extent of nontimber resource extraction in tropical forests: accessibility to game vertebrates by hunters in the Amazon basin. Conserv Biol 17:521-535

Siemers BM (2000) Seasonal variation in food resource and forest strata use by brown capuchin monkeys (Cebus apella) in a disturbed forest fragment. Folia Primatol 71: 181-184

Sih A, Jonsson BG, Luikart G (2000) Habitat loss: ecological, evolutionary and genetic consequences. Trends Ecol Evol 15:132-134

Soulé ME, Bolger DT, Alberts AC, Wright J, Sorice M, Hill S (1988) Reconstructed dynamics of rapid extinctions of chaparral-requiring birds in urban habitat islands. Conserv Biol 2:75-92

Strier KB (1992) Atelinae adaptations: behavioral strategies and ecological constraints. Am J Phys Anthropol 88: 515-524

Symington MM (1988) Demography, ranging patterns, and activity budgets of the black spider monkeys (Ateles paniscus chamek) in the Manu National Park, Peru. Am J Primatol 15:45-67

Thomas L, Lake JL, Strindberg S, Marques FFC and others (2006) Distance. Research Unit for Wildlife Population Assessment, University of St. Andrews. Available at www. ruwpa.st-and.ac.uk/distance/

Urbani B, Morales AL, Link A, Stevenson P (2008) Ateles hybridus. In: 2008 IUCN Red List of Threatened Species. www.iucnredlist.org

Vargas LS, Camacho S, Roman LR (1998) Diagnostico socioeconómico de municipios productivos en el Magdalena Medio Colombiano. Available at www.angelfire.com/ia2/ ingenieriaagricola/madalenamedio.htm

Wieczkowski J (2004) Ecological correlates of abundance in the Tana mangabey (Cercocebus galeritus). Am J Primatol 63:125-138

Submitted: November 5, 2009; Accepted: September 8, 2010 Proofs received from author(s): November 14, 2010 